\title{
Circular Economy Policies in China and Europe
}

Will McDowall*, Yong Geng, Beijia Huang, Eva Barteková, Raimund Bleischwitz, Serdar Türkeli, René Kemp, Teresa Doménech

*UCL Institute for Sustainable Resources, 14 Upper Woburn Place, London WC1H ONN, UK. w.mcdowall@ucl.ac.uk

\section{Summary}

The idea of a Circular Economy has become prominent in both European and Chinese policymaking. Chinese and European perspectives on a circular economy share a common conceptual basis and exhibit many similar concerns in seeking to enhance resource efficiency. Yet they also differ, and this paper explores differences in the focus of CE policy in China and Europe.

We present evidence on the differing understandings of the CE concept in Chinese and European policy discourse, drawing on qualitative and quantitative analysis of policy documents, media articles and academic publications. We show that the Chinese perspective on the circular economy is broad, incorporating pollution and other issues alongside waste and resource concerns, and it is framed as a response to the environmental challenges created by rapid growth and industrialization. In contrast, Europe's conception of the CE has a narrower environmental scope, focusing more narrowly on waste and resources, and opportunities for business. 
We then examine similarities and differences in the focus of policy activity in the two regions, and in the indicators used to measure progress. We show differences in the treatment of issues of scale and place, and different priorities across value chains (from design to manufacture, consumption and waste management). We suggest some reasons for the divergent policy articulation of the CE concept, and suggest lessons that each region can learn from the other.

\section{Introduction}

China and Europe face a number of structural economic challenges. Growth rates remain lower than expected in both regions, while environmental and social challenges demand attention. The linear model of production - based on a 'take, make and dispose' approach which relies on imports of virgin natural resources and disposal of wastes and emissions - appears increasingly outdated. Both regions have adopted the idea of a "circular economy" in pursuit of a more sustainable use of natural resources.

However, the policy articulation - and even the meaning-of the "circular economy" (CE) differs in these regions. This article presents a comparative analysis of CE policy approaches in China and Europe. In particular, we seek to identify differences in the way in which the CE is understood and described in the two regions. The merits of a comparative approach should be obvious: there are substantial opportunities for mutual learning from the experiences in different regions. Moreover, a comparative perspective can inform emerging international efforts to promote a circular economy. 
This article first provides some background on the development of CE policy in each region. We then explore how the CE is framed within Europe and China, drawing on analysis of policy documents, media content analysis, and a bibliometric analysis of scientific publications. We then examine similarities and differences in the focus of policy activity, and in the indicators used to measure progress towards the circular economy.

\section{Circular Economy Policy in China and Europe: background and}

\section{brief history}

\section{Origins}

The CE concept emerged in Europe in the 1980s and 1990s (e.g. (Pearce and Turner 1990)), together with early policies of EU member states, drawing on ideas that can be traced to the 1970s (Stahel and Reday 1977). Driven by a desire to divert waste from landfill, The Netherlands and Germany pioneered concepts of waste prevention and reduction, with the waste hierarchy introduced to the Dutch Parliament in 1979 (Parto et al. 2007).

\section{CE policy in China}

The concept of CE in China was introduced in the 1990s. It had origins in cleaner production, industrial ecology and ecological modernization thinking, and was inspired by examples of implementation in Europe, US and Japan (Shi et al. 2006; CCICED 2005). The concept of a CE was formally accepted in 2002 by the central government as a new development strategy. China's main national-level framework for pursuing the CE is the "Circular Economy Promotion Law", which came into force in 2009 (National People's 
Congress 2008a). Various action plans have followed (e.g. (State Council 2013)), which provide further details for specific sectors and provide clarity on the implementation of the provisions of the CE promotion law. Further details of China's policy framework have been provided in a number of publications (e.g. (Geng et al. 2016; Geng et al. 2012; Geng and Doberstein 2008; Su et al. 2013; Mathews and Tan 2016) in recent years.

\section{CE Policy in Europe}

Despite its European origins, the CE has only very recently become prominent at the highest levels of European policymaking. Following concern around high commodity prices, the European Commission launched a 'flagship' initiative on resource efficiency, which was first operationalized through the 'roadmap for a resource efficient Europe' (2011). This was followed-up with the announcement of a range of policy measures known collectively as the "Circular Economy Package". This was later replaced by the "Closing the Loop- An Action Plan for the Circular Economy ${ }^{1}$ (European Commission 2015a).

The Action Plan sets out a policy framework that builds on and integrates existing policies and legal instruments. In particular, the European CE Action Plan proposes amendments to legislation relating to waste and landfills (which were due for revision). The Action Plan also proposes various new initiatives. Key elements of the action plan are shown in Table 1.

\footnotetext{
${ }^{1}$ Note that the Action Plan has yet to be approved by the European Parliament and Council
} 
Table 1. Summary of the EU 2015 Action Plan for the Circular Economy, with examples of specific policies

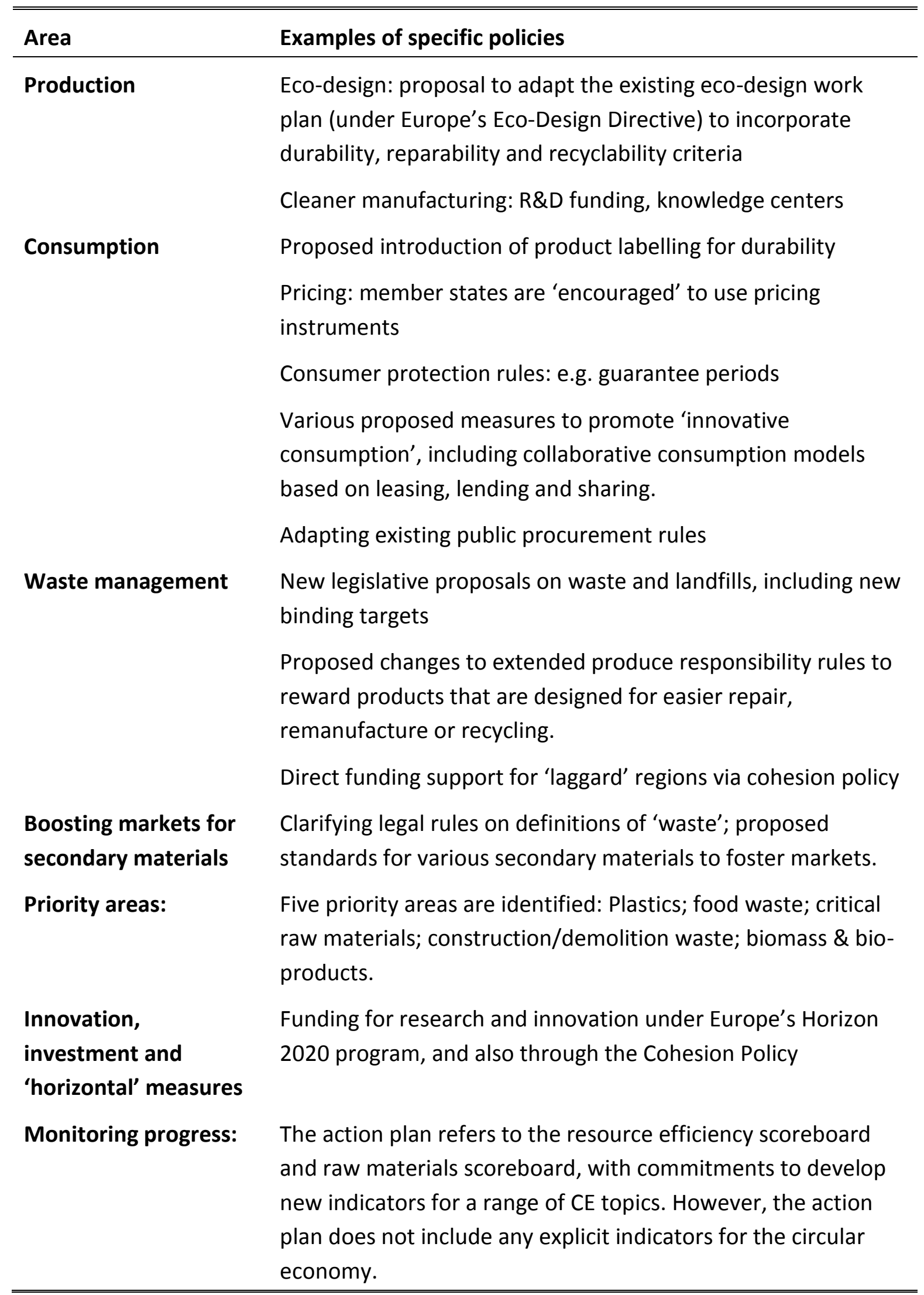


Under the overall European approach, member states (MS) vary considerably in their CE aspirations and approaches. A small number of MSs (Germany, Austria and Finland) have dedicated strategies for resource efficiency and the circular economy, though only Austria has identified targets and a clear timeline. Several have introduced construction material or other resource taxes (Bahn-Walkowiak et al. 2012).

\section{Circular economy: common and differing perspectives in China and Europe}

The idea of a CE can be understood as a narrative frame that corresponds to a broad set of related policy goals. Narratives and discourses have been recognized to play important roles in environmental policy (Hajer 1995; Rydin and Ockwell 2010), shaping the behavior of actors and the negotiation of policies. The CE is sufficiently broad in scope that it offers the potential for interpretive flexibility, i.e. it can be understood or applied differently in different contexts, and accommodate a broad range of policy interests.

This section offers some insights into how the concept is understood and articulated in both regions. A combination of methods has been used to provide insight into two questions: i) Are Chinese and European policymakers invoking the concept as a solution to similar policy problems? ii) Do Chinese and European conceptions of the CE differ in scope or focus? Each of the methods used has limitations, but combined they provide a good picture of the way in which the circular economy concept is applied. 


\section{Thematic analysis of policy documents}

A qualitative content analysis was carried out on Chinese and European policy documents relating to the $\mathrm{CE}$ using thematic analysis. The main purpose of this was to identify both divergent and overlapping themes in the way that the CE was articulated in policy documents. Further details of the specific texts, and the coding scheme used in the analysis, are available as supplementary material.

In both regions, the CE can be seen as an embodiment of 'ecological modernization' - the idea that conflicts between environment and economy can be overcome through innovation, both technical but also social (e.g. new business models). There are strong parallels in both regions, reflecting the common underlying conceptual core of the CE idea: both describe the circular economy as a new model for reconciling economic and environmental imperatives. However, within that broad framing there are differences.

The problem framing (i.e. the problems that the CE is invoked to solve) in Chinese policy documents is that rapid industrialization and growth have brought with them serious environmental damages, and that China needs a new model to reconcile continued growth with wider environmental concerns. The major CE policy documents take continued economic growth as a given: the problem is not in stimulating economic activity, but rather it is aligning continued growth with environmental and social concerns. This can be illustrated with the following quote:

"Since the eighties of last century, China's rapid economic growth has resulted in great achievements, but has also used a lot of resources and created environmental costs. Economic development and resource and environmental issues have become increasingly acute contradictions.... Therefore, it is necessary to change the economic growth model..."

(National People's Congress 2008b) 
This follows the close association of the CE concept with the efforts of Hu Jintao's administration to articulate an attempt to rebalance policy to take account of environmental and social as well as economic objectives, a goal described as 'harmonious development' (Weng et al. 2015). Since 2007, the concept of 'ecological civilization' (生态文 明) has been promoted as the Chinese Communist Party's long term vision of sustainable development (Geall 2015b; Geng et al. 2016), and the CE is one of the underlying principles of both ecological civilization (Geall 2015a) and harmonious development (Naustdalslid 2014). Thus the CE concept lies at the heart of Chinese environmental political rhetoric. In contrast, within European policy documents the rationale for CE policy is presented as relating to economic competitiveness and innovation as much as environmental goals. Unlike in China, the CE is framed as a response to an explicit need to foster growth, and to do so in a way that meets environmental constraints, through resource efficiency, innovation and capturing the value of wastes as secondary raw materials. The $\mathrm{CE}$ is thus framed as a way of turning environmental necessity into economic opportunity. This follows the CE's close association with European policy discourse around resource efficiency (Miedzinski 2015). This is illustrated by the following quote from the speech made at the launch of the CE package in 2015:

"We cannot compete on wage costs; we cannot compete on cheap natural resources as other parts of the world could. But with resource efficiency, leadership in green technologies and modern waste management, we can build a competitive edge, generate new business opportunities and create jobs."

(Timmermans 2015) 
In addition to different problem frames, there are also differences in the breadth of the CE concept. In European policy rhetoric, the emphasis is on materials, resources and waste, and much less on wider environmental pollution. In contrast, the view of the CE in Chinese policy documents is broader. While incorporating materials, resources and waste, the Chinese perspective includes a prominent role for pollution concerns, as well as the need to build a "resource saving and environment-friendly society" (State Council 2005), and "ecological civilization" (State Council 2013).

In addition to the qualitative content analysis described above, a quantitative textanalytic approach was applied to the policy documents (details of this analysis are available as supplementary material). This analysis used natural language processing to identify all noun phrases (e.g. "circular economy", "new business model"), across a set of European and Chinese policy documents. Comparison of the most frequently used nouns and noun phrases provides a sense of the relative weight that these concepts receive. Though such counts are a simple measure, they provide a reproducible way of triangulating the findings of the qualitative analysis. The results agree with the qualitative analysis: Chinese policy documents mention 'pollution' much more frequently than their European counterparts. Both sets of documents have prominent roles for both waste and resources. Innovation emerges as a highly used term in the European texts, and it appears only rarely in the Chinese documents. Similarly, business models and business model innovation also appear much more frequently in the European texts.

\section{Media Representations}

Media content analysis (Macnamara 2005) can help reveal the way in which the concept of a circular economy is described within public discourse in China and Europe. 
Using databases of newspapers, it is possible to examine the prevalence of the CE concept, and the extent to which the CE co-occurs with related environmental issues.

The analysis is based on newspapers from China, the UK, Germany, Italy, Spain, France and the Netherlands. Articles using the term "circular economy" were identified, and additional searches were then made for the following terms (and their appropriate translations): Sustainable development, resources, waste, and pollution. The proportion of articles discussing the CE that also discuss each of the other terms was then calculated. Full details of the newspaper sources and search terms used, and the country-level results, are available as supplementary materials.
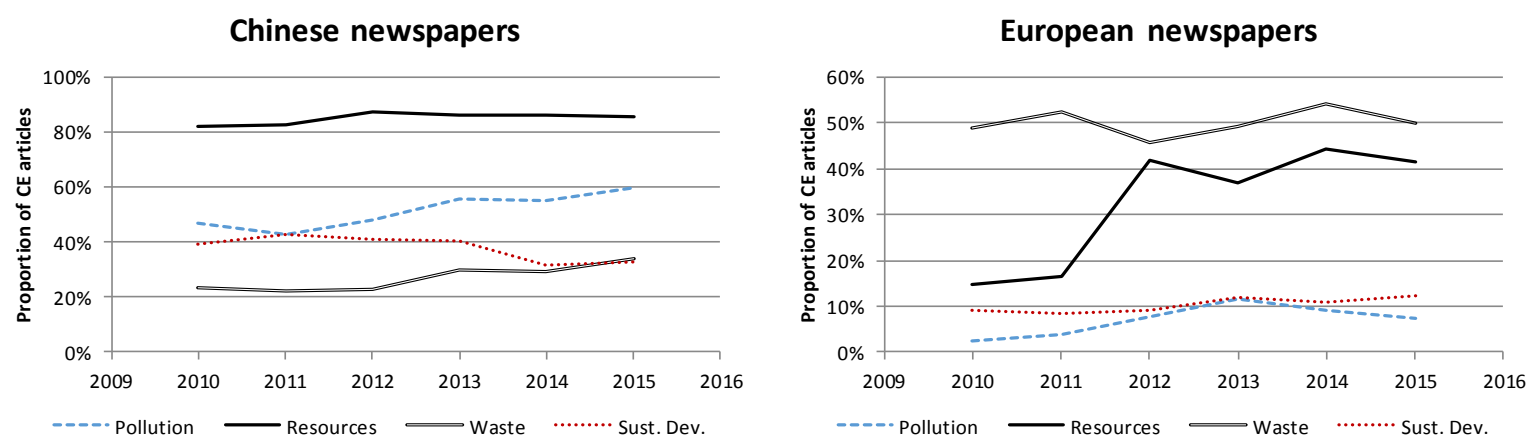

Figure 1. The proportion of articles mentioning the 'circular economy' that also mention pollution, resources, waste or sustainable development.

The results of the media content analysis are shown in Figure 1. Common to both European and Chinese media is the prominence of 'resources' in discussions of a circular economy. However, differences are clear: 'pollution' is much more prominent in discussions about a CE in China than in Europe; whereas European debates place greater emphasis on 'waste'. 


\section{Framing in academic research}

A bibliometric analysis using the Web of Science and Scopus databases was also undertaken to explore different framings of the CE in journal articles written by Chinese and European researchers. This analysis identified articles discussing the CE ( $n=229$ for EU-28 and 141 for China, Web of Science (WoS); $n=374$ for EU-28 and 748 for China, SCOPUS), and identified the share of those articles that also discussed waste, pollution and other key terms. Bibliometric analysis reflects the findings of the media content analysis: European publications on the CE are more likely to discuss waste ( $55 \%$ of CE publications in WoS; $\sim 69 \%$ in Scopus) than their Chinese counterparts ( $37 \%$ of CE publications in WoS, $\sim 35 \%$ in Scopus) $)^{2}$. The term "pollution" is used more in CE publications from China than in those from Europe ( $21 \%$ against $\sim 7 \%$ based on WoS data; $28 \%$ against $\sim 23 \%$ based on SCOPUS data $)^{3}$. Full details of the method and findings are reported in supplementary material.

\section{Summary}

The three analytic approaches outlined above (on policy documents, media and in research) arrive at a similar conclusion: Chinese and European perspectives on a circular economy share a common conceptual basis and exhibit many similar concerns in seeking to enhance resource efficiency. Yet they also differ in their emphases. The Chinese version of the circular economy is more closely linked to pollution and to the broader category of sustainable development (and to ecological civilization; Weng et al. (2015)), whereas the European versions are focused on waste and opportunities for industry.

\footnotetext{
2 The percentages are the percentage of publications mentioning "circular economy" written in the EU and China and included in the Thomson Reuters Web of ScienceTM Core Collection and SCOPUS as of January 1st 2017 that contain the word "waste".

3 Percentages are calculated as for 'waste', described in note 2.
} 


\section{Divergences in the focus of policy activity}

Having established differences in the way in which the circular economy is described and framed, we now turn to the differing focus of CE policy activity in Europe and in China, drawing on an analysis of policy documents. While the Chinese and European policy approaches (as embodied in the various action plans and laws) have many similarities, we examine two dimensions in which the focus of policy activity has diverged, and in discussing each we suggest possible explanations.

\section{Focus of policy attention: across the value chain}

Analysis of policy documents makes clear that Chinese and European CE policies share a concern with waste and with resources. Key elements of Europe's 2015 Action Plan are the legislative proposals on waste, and the concern for raw materials and resource efficiency is clear. Similarly, Chinese circular economy policies include substantial focus on municipal waste, industrial waste and wastewater, as well as resources. However, differences are also clear. In particular, European CE policies focus on consumption and product design more than is the case in China:

- Europe has a well-developed eco-design system, covering a wide range of household goods. The European CE Action Plan makes clear the intention to extend that system to include attributes of relevance for a $\mathrm{CE}$, including product durability, repairability and recyclability. While China's CE Promotion Law includes some commitments to eco-design, and announces an intention to restrict disposable consumption goods, the system of product-level eco-design is far less developed in China compared to Europe (MIIT and European Commission 2014). 
- Europe is considering the introduction of mandatory product labelling for durability, enabling consumers to buy more durable products, and hence reducing demand for replacement goods.

- The Action Plan proposes a number of measures for fostering innovative forms of consumption that reduce material demands, through fostering innovation in business models that facilitate sharing or the replacement of goods with services. China's CE Promotion Law does include concern for eco-design (Article 19), and potential product regulations on some classes of disposable goods (Article 28), and the 2013 State Council Action Plan does include sections on green consumption (State Council 2013). More recent announcements (NDRC 2016) have also highlighted proposals for restrictions on disposable goods. These do not, however, match the scale or scope of existing and proposed European efforts around eco-design, durability labelling and consumption-oriented measures.

Overall, despite the explicit framing of China's CE as based on the principle of 'reduce, re-use, recycle', with priority for actions to 'reduce', China's plans and strategies place less emphasis on measures to influence patterns of consumption. Rather, there is greater focus on detailed coverage of specific manufacturing sectors and measures to increase efficiency and reduce waste and pollution in manufacturing. This reflects the differences in framing discussed above, to the extent that Chinese CE policy shows a greater concern for industrial pollution.

How might these divergent priorities for circular economy policy be explained? One plausible explanation may be the industrial structures in China and Europe. Manufacturing and exports play a much larger role in China's economy, with implications for industrial activity and pollution. In this context, China's focus within CE policy on pollution and cleaner 
production should come as no surprise. In contrast, Europe's economy is more reliant on domestic consumption (with consequently high waste streams associated with consumption). This goes some way to explaining the relative European emphasis on waste and consumption patterns.

\section{Focus of policy attention: scale and place}

A second way in which the focus of policy activity has diverged relates to the treatment of spatial dimensions of the CE. The European approach is almost entirely silent on issues of space and place, other than noting that all levels of government across Europe have roles to play. In contrast, issues of scale and geography are important in China's model, in two distinct ways.

First, China's CE policy includes an explicit concern for the integration of CE principles into land-use planning (see, e.g. Articles 29 and 37 of the CE Promotion Law). One reason for this is China's ongoing rural-urban transition: the growth of new urban and industrial areas has created challenges for land-use planners. The focus of CE policy on environmentally-sensitive spatial integration of residential, agricultural and industrial activities reflects those concerns. This is very different from the European situation, where urban development is not occurring on the same scale.

Second, a distinctive feature of China's CE policies is the designation and funding of specific provinces, cities or 'zones' (such as industrial parks ${ }^{4}$ ) as CE pilots or demonstrations (Zhang et al. 2010; Weng et al. 2015; Geng et al. 2012; Mathews and Tan 2016). This 
approach spans geographic scales: from cities to individual enterprises (more than one hundred enterprises have qualified as 'CE demonstration enterprises' (Geng et al. 2012)). Municipal or industrial park authorities (or managers, in the case of enterprises) can apply to the NDRC for a designation, and are then assessed against key performance targets. Designated entities receive funding from the NDRC, and seeking such designations can be an important part of local economic strategy. Thieriot and Sawyer (2015) estimated that the average subsidy per circular economy park designated in 2012 was around 182 million RMB.

Regional pilot zones are a frequently used governance tool in China (Heilmann 2008a, 2008b; Zhao et al. 2016). Designations of this kind are used by both central and provincial governments, leading to an array of 'special zones' (low carbon, eco-industrial, circular economy, etc.), with areas often receiving multiple designations. Lessons from designated experimental zones are, in theory, then used as a basis for informing future policymaking (see, e.g. State Council (2013), which refers to the lessons learnt from 60 circular economy pilots). Heilmann has characterized this approach as 'experimentation under hierarchy', and illustrated how it forms part of a wider emphasis on experimentation and gradualism within Chinese governance (Heilmann 2008b, 2008a).

Zhao et al. (2016) have highlighted the globally distinctive nature of this governance approach in the context of low-carbon development, and they argue that China's use of experimental zones is partly a response to China's well-known environmental policy implementation gap. Environmental policies in China have often been subservient to economic imperatives at the local level, resulting in a considerable implementation gap (Lo 2014; Zheng 2011). The implementation gap is exacerbated by the tax system, which encourages local governments to focus on local growth in order to supplement budgets 
(Shen 2011), and the lack of specificity in many of China's environmental laws (Wang and Wang 2011).

Central government designations of zones (and the associated funds) can to a limited extent by-pass the implementation gap, in that they provide direct incentives to meet CE goals. Given the relatively small share of economic activity covered by such designations (Thieriot and Sawyer 2015), the wider impact is limited. However, industrial parks in general account for a large share of Chinese manufacturing output (around 50\%; Mathews and Tan (2016)), and upscaling experiments piloted in designated parks could provide a mechanism for wider application. Indeed, the evidence from both cities (Geng et al. 2009b; Su et al. 2013) and industrial parks (Yu et al. 2015) is that designated regions have shown improvements against relevant performance indicators, though these studies also make clear that implementation challenges remain.

There are analogues of China's experimental governance in Europe's system. Part of the European model is that innovative policies are pioneered by leading member states, suggesting important roles for the European semester (the process by which divergent experiences and policies are assessed across Europe, enabling policy learning) and the Cohesion Policy (which funds the development of regions that are less advanced, facilitating policy diffusion to less developed regions). Europe's Horizon 2020 program also includes funds for "large-scale demonstrations", though the scale of these is considerably smaller than the funding for China's experimental circular economy zones. In short, China's approach to experimentation for the CE across geographic scales embeds a more structured approach. 


\section{Measuring progress towards the CE}

Both Chinese and European CE policies identify the need for indicator systems to monitor progress. Here, we first examine the roles of targets and indicators in Europe and China, before examining what the different systems reveal about the concerns of CE policymakers in the two regions.

\section{CE indicators and targets in Europe}

In Europe, indicators are used to inform the policy debate (though their impact is often limited (Lehtonen 2013; Lehtonen 2015)), while targets are often established as goals for member states. Many targets are binding on member states, with penalties for noncompliance. The EU's 2015 CE Action Plan proposes a number of targets that are binding on member states, all of which relate to various waste streams. These include recycling targets (65\% of municipal waste and $75 \%$ of packaging waste should be recycled by 2030 ), landfill targets (no more than $10 \%$ of municipal waste to landfill by 2030 ).

The European Commission has so far refrained from embracing an explicit set of circular economy indicators. The CE Action Plan (European Commission 2015a) highlights the need for such a set, but addresses this need by referring to existing indicator sets (the Resource Efficiency Scoreboard and the Raw Materials Scoreboard), and by committing to develop indicators in the future.

The Resource Efficiency Scoreboard establishes a hierarchy of indicators, with resource productivity (measured as GDP/Raw Material Consumption) the 'headline' indicator (European Commission 2015b). 
The first Raw Materials Scoreboard report (Vidal-Legaz et al. 2016) includes a range of relevant indicators. In particular, it includes an "end-of-life recycling input rate" indicator, which relates to the proportion of inputs into an industry that are derived from recycled goods (unlike typical recycling metrics, which use waste streams as a denominator). It also provides a number of metrics relevant to the European emphasis on innovation (recyclingrelated patents) and economic aspects of the CE (value of trade in secondary raw materials). There are currently no indicators in either scoreboard relating to the unique aspects of Europe's CE approach, such as indictors on eco-design or product durability.

\section{CE indicators and targets in China}

China's governance system involves a key role for targets, through 'target responsibility systems' (目标责任制; see (Lo 2014; Minzner 2009; Liu et al. 2012; Brettell 2013)). In this system, the career advancement of officials at subsidiary levels of government is tied to performance against targets derived from the Five Year Plan. In this context, regulations issued by central government may be enforced less in terms of the letter of the law, and more through evaluations against indicators (Young et al. 2015) 5

It is notable in this regard that China's Circular Economy Promotion Law requires the establishment of target responsibility systems in support of the circular economy; and notes that progress against indicators should be used in the performance evaluations of senior officials. The $11^{\text {th }}$ and $12^{\text {th }}$ Five Year Plans set out the relevant targets (including energy and water intensity of GDP, industrial solid waste generation and reuse, industrial water re-use,

\footnotetext{
${ }^{5}$ This system can lead to perverse outcomes: ambitious energy intensity targets in the $11^{\text {th }}$ Five Year Plan resulted in local officials ordering the temporary shutdown of businesses and even hospitals in bid to meet targets (Feng and Yuan 2011).
} 
irrigation efficiency, and recovery rates for recyclable materials). However, many of these indicators should not be seen solely through a 'CE' lens, as they are also associated with other policy initiatives (some of which precede the emergence of the CE as a policy concern).

In addition to binding CE targets, China also has an extensive system of indicators, with specific indicator sets developed for three levels: micro (firm-level), meso (ecoindustrial park) and macro (city or province). These are an important component of the strategy of regional experimentation through pilot zones. Industrial parks and cities apply for designated status based on an action plan that sets out anticipated progress against key indicators. The indicators are thus voluntary, in the sense that only entities wishing to apply for designated status need to monitor and report on them. Having a consistent set of national indicators with which to understand, compare and measure progress of these various pilots is necessary for their effective implementation - and such indicators must be appropriate to the spatial scale of the initiatives, hence China's multi-level system.

These multi-level indicators have been subject to extensive analysis and discussion within the literature (see e.g. Geng et al. (2012); Zhang et al. (2010); Geng et al. (2009a)). In particular, the indicators have been criticized due to the lack of social indicators, absolute emission reduction indicators, absolute material/energy reduction indicators, and prevention-oriented indicators (Geng et al. 2012; Geng et al. 2013; Geng et al. 2016). Moreover, there is no detailed description or standardized process on data collection, calculation and submission. Finally, the NDRC only provides general lists of indicators that should be reported, but they do not provide specific goals and values that may be used as benchmarks (Geng et al. 2012). Consequently, significant improvement on these indicators are important. 
More recently, and in order to provide a simpler, national-level picture to inform ongoing policy, China's National Bureau of Statistics (NBS) has constructed a single composite indicator of China's progress towards a circular economy (NBS 2015). In terms of function, this indicator is more directly equivalent to the EU indicator sets that are intended to provide an overall picture of relevance to policy, but which otherwise do not play a direct governance role.

The indicator, and its constituent four sub-indicators, is shown in Figure 2 for the years 2005-2013. These four sub-indicators are all themselves composites developed from further indicators (e.g. industrial solid waste per unit industrial added value; $\mathrm{SO}_{2}$ emissions per unit GDP, water consumption per unit GDP).

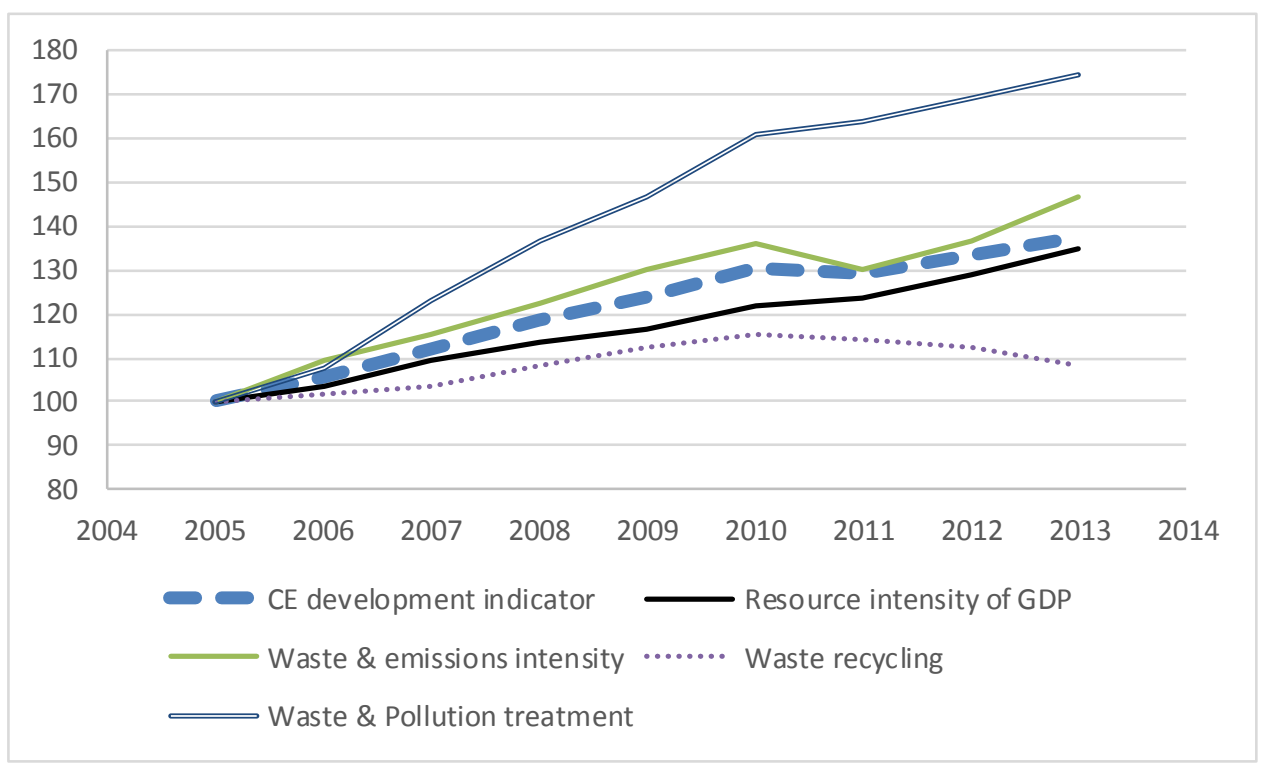

Figure 2. China's progress towards a circular economy, as reported by the National Bureau of Statistics. All sub-indicators are expressed as improvements relative to 2005 .

Finally, (Ma and Ortolano 2000) discuss the relevance of the Chinese concept of 'face' for achieving environmental policy goals via informal, rather than formal, institutional structures. In a set of case studies, they found that meeting government indicators, and 
winning environmental awards, was seen as a way to 'gain face' by local enterprises. In the same way, officials and enterprises may see poor performance against formal indicators as causing a loss of face, and thus may make efforts to meet them even in the absence of formal incentives.

\section{Insights from indicators into the concerns of policymakers}

The indicators and targets are revealing in the differences that they demonstrate between the European and Chinese approaches to the CE. Chinese indicators and targets include several pollution emission and abatement indicators (which are largely absent from the relevant EU indicators and targets), and prominent coverage of water (which is included, but not prominent, in the EU Resource Efficiency Scoreboard). Chinese indicators also work across geographic scales, reflecting China's multi-level view of CE implementation.

In contrast, the European targets related to the CE are specific to various waste streams. Key indicators relate primarily to resource productivity and raw materials. They also reflect Europe's concern with innovation and economic aspects of the CE. It is worth noting that Europe has extensive systems of targets and indicators that do cover many of the issues captured in China's more extensive CE indicators (such as $\mathrm{SO}_{2}$ emissions), but these are typically not associated with the CE in policy discussions (see, e.g. the list of European environmental policy targets in (EEA 2013)). 


\section{Conclusions: Towards Mutual Learning for CE Governance?}

This article has shown that despite a shared conceptual basis, the CE is framed differently in China and Europe. Moreover, despite many shared goals, particularly around resources, the focus of CE policymaking also shows key differences, rooted in different industrial structures and different governance systems.

In summary, China's approach to the CE reflects a greater concern with industrial production, water, pollution, and places greater attention to scale (through a multi-level system of 'experimentation under hierarchy') and place (through incorporation of CE ideas into land-use planning). CE policy is framed as part of a wider response to the environmental challenges created by rapid growth and industrialization. Europe's conception of the CE has a narrower environmental scope, focusing on waste and resources, with little regard for pollution, and Europe's view is largely silent on issues of scale or place. Europe's CE policies are framed in economic as much as environmental terms, focusing on the potential for resource efficiency to boost competitiveness. These differences suggest a need for caution in drawing direct equivalence between efforts for a circular economy in different regions (c.f. (Mathews and Tan 2016)), and suggest a need for greater mutual understanding to facilitate collaboration and lesson-drawing.

It is clear that the divergent contexts of the two regions preclude the simple transfer of policy lessons from one to another, not least because of the differing governance paradigms examined above, and the fact that China is a sovereign state while the EU is a supranational organization. However, both regions can be considered forerunners on the topic and each region's approach to implementation of the CE concept contains lessons for the other, and key lessons are drawn here. 
Lessons for Europe from China:

First, China's approach to the CE involves a major program of experimentation at different scales, through the designation of zones, regions, and cities. This goes beyond the large-scale demonstrations funded by Europe's Horizon 2020 program, and it is more coordinated than the experimentation that occurs among EU member states - and it appears to be more geared towards upscaling successes. In its focus on creating arenas for transition experiments, focused on leading firms and institutions, the Chinese approach bears some resemblance to the prescriptions of 'transition management' (Kemp et al. 2007) and attempts at green innovation-led development in transition 'regions' (Cooke 2011). The blend of coordinated administration, as well as encouragement and facilitation of local experimentation (see also (Zhao et al. 2016)) provide a governance model that could provide important lessons for the structuring of large-scale demonstrations or sociotechnical experiments within the European context. This is particularly relevant in Europe, given a recognized need to move beyond fostering best practice in "niches" towards upscaling and mainstreaming promising innovations (Bleischwitz et al, 2014).

Second, China's experiences with indicators, particularly those that are specific to different spatial scales, may provide lessons for Europe's attempts to develop indicators in support of the EU's CE Action Plan. However, the different understandings of the CE also suggest caution here: for example, Chinese CE indicator sets typically include classic pollution indicators such as $\mathrm{SO}_{2}$ emissions, which would not be seen as relevant for CE policy by many European policymakers. Moreover, the substantial overlap between China's CE indicators and indicators for other areas of policy (such as energy efficiency, pollution 
prevention, and so on) makes it harder to identify the additional impacts of CE policy compared to other environmental policy initiatives.

Third, China's approach to the CE incorporates aspects of land-use planning within a broader eco-industrial development framework. There may be lessons here for both member states (at the level of national urban planning frameworks) or for European institutions involved in regional development (e.g. through Cohesion funds) to incorporate CE principles into land-use planning and urban design.

Lessons for China from Europe:

First, as China makes a transition towards higher domestic consumption, there will be opportunities to learn from European experience in attempting to manage the material flow consequences of consumption through a CE perspective. In particular, China can learn from Europe's experiences of the Eco-Design process, from providing incentives to producers to make products easier to repair, remanufacture and recycle, and from efforts to promote business model innovation.

Second, European product labelling requirements have, in the past, provided a model followed by many other countries, including China. If Europe continues to develop mandatory product durability labelling, this would provide direct lessons that could be used as a model for similar initiatives in China.

Third, emerging European indicator systems account for issues that have hitherto not been incorporated within Chinese CE indicators, such as patents in recycling technologies. As the Chinese CE indicator systems further develop, there may be value for China in adopting some of these broader indicators that enable monitoring of CE-specific economic activities. 
Finally, there are opportunities for synergies between China and the EU. The large

trade flows between the two regions suggest a number of areas in which agreed indicators, standards, and mutual learning could facilitate the development of a circular economy within both regions and beyond. Such areas include efforts to shape product design for durability, repairability and recycling; standards for products, eco-industrial processes and secondary materials; policy coordination on primary industries such as steel; and evidence on the effectiveness of policy instruments.

\section{Acknowledgements}

This study is financially supported by National Natural Science Foundation of China (71461137008, 71325006, 71403170); the UK Economic and Social Science Research Council (ES/L015838/1); and the Netherlands (467-14-154), through the collaborative SinoEuropean Circular Economy and Resource Efficiency (SINCERE) project.

\section{References}

Bahn-Walkowiak, B., R. Bleischwitz, M. Distelkamp, and M. Meyer. 2012. Taxing construction minerals: a contribution to a resource-efficient Europe. Mineral economics 25(1): 29-43.

Brettell, A. 2013. A Survey of Environmental Deterrence in China's Evolving Regulatory Framework. In Chinese Environmental Governance: Dynamics, Challenges and Prospects in a Changing Society, edited by B. Ren and H. Shou. New York: Palgrave Macmillan.

CCICED. 2005. Report on Circular Economy (2005).

http://www.cciced.net/encciced/policyresearch/report/201205/t20120529_230487.html. Accessed 08-11-2015.

Cooke, P. 2011. Transition regions: Regional-national eco-innovation systems and strategies. Progress in Planning 76(3): 105-146.

EEA. 2013. Towards a green economy in Europe: EU policy targets and objectives 2010-2050. EEA Report No 8/2013, ISSN 1725-9177. European Environment Agency, Copehagen.

European Commission. 2015a. Closing the loop: an action plan for the circular economy.

European Commission. 2015b. Resource Efficiency Scoreboard 2015. Report published by the European Commission, Brussels. 
Feng, J. and D. Yuan. 2011. Behind China's green goals. In China's green revolution: energy, environment and the 12th Five Year Plan. London and Beijing. Available online at www.chinadialogue.net: Chinadialogue.

Geall, S. 2015a. Interpreting Ecological Civilisation (Part Two). In China Dialogue.

Geall, S. 2015b. Interpreting Ecological Civilisation (Part One). In China Dialogue.

Geng, Y. and B. Doberstein. 2008. Developing the circular economy in China: Challenges and opportunities for achieving 'leapfrog development'. International Journal of Sustainable Development \& World Ecology 15(3): 231-239.

Geng, Y., J. Sarkis, and S. Ulgiati. 2016. Sustainability, well-being, and the circular economy in China and worldwide. Science(6278 (Suppl.)): 73-76.

Geng, Y., P. Zhang, R. P. Côté, and T. Fujita. 2009a. Assessment of the National Eco-Industrial Park Standard for Promoting Industrial Symbiosis in China. Journal of Industrial Ecology 13(1): 1526.

Geng, Y., Q. Zhu, B. Doberstein, and T. Fujita. 2009b. Implementing China's circular economy concept at the regional level: A review of progress in Dalian, China. Waste Management 29(2): 9961002.

Geng, Y., J. Fu, J. Sarkis, and B. Xue. 2012. Towards a national circular economy indicator system in China: an evaluation and critical analysis. Journal of Cleaner Production 23(1): 216-224.

Geng, Y., J. Sarkis, S. Ulgiati, and P. Zhang. 2013. Measuring China's Circular Economy. Science 339(6127): 1526-1527.

Hajer, M. A. 1995. The politics of environmental discourse: ecological modernization and the policy process: Clarendon Press Oxford.

Heilmann, S. 2008a. From local experiments to national policy: The origins of China's distinctive policy process. The China Journal: 1-30.

Heilmann, S. 2008b. Policy experimentation in China's economic rise. Studies in Comparative International Development 43(1): 1-26.

Kemp, R., D. Loorbach, and J. Rotmans. 2007. Transition management as a model for managing processes of co-evolution towards sustainable development. International Journal of Sustainable Development and World Ecology 14(1): 78-91.

Lehtonen, M. 2013. The non-use and influence of UK energy sector indicators. Ecological Indicators 35: 24-34.

Lehtonen, M. 2015. Indicators: 'tools' for policy formulation or an inexhaustible source of unanticipated impacts? In The Tools of Policy Formulation. , edited by A. Jordan and J. Turnpenny. Cheltenham: Edward Elgar.

Liu, L., B. Zhang, and J. Bi. 2012. Reforming China's multi-level environmental governance: Lessons from the 11th Five-Year Plan. Environmental Science \& Policy 21: 106-111.

Lo, K. 2014. China's low-carbon city initiatives: The implementation gap and the limits of the target responsibility system. Habitat International 42: 236-244.

$\mathrm{Ma}, \mathrm{X}$. and L. Ortolano. 2000. Environmental regulation in China: Institutions, enforcement, and compliance: Rowman \& Littlefield Publishers.

Macnamara, J. R. 2005. Media content analysis: Its uses, benefits and best practice methodology. Asia-Pacific Public Relations Journal 6(1): 1-34.

Mathews, J. A. and H. Tan. 2016. Circular Economy: Lessons from China. Nature 531(7595): 440-442.

Miedzinski, M. 2015. Public policy for long-term societal challenges? The reframing of policy narratives and the 'Roadmap to a Resource Efficient Europe'. PhD Thesis, University of Manchester. thesis.

MIIT and European Commission. 2014. China-EU eco-design product policy research and information report. Joint research report from the European Commission and the Ministry of Industry and Information Technology of the People's Republic of China, prepared under the EU-China Policy Dialogues Support Facility Il; published on 11 December 2014 in Beijing and Brussels. 
Minzner, C. F. 2009. Riots and cover-ups: counterproductive control of local agents in China. University of Pennsylvania Journal of International Law 31.

National People's Congress. 2008a. People's Republic of China Circular Economy Promotion Law. (中 华人民共和国循环经济促进法). Standing Committee of the Fourth Session of the Eleventh National People's Congress August 29, 2008. Beijing. In Chinese. Available online at http://www.gov.cn/flfg/2008-08/29/content_1084355.htm.

National People's Congress. 2008b. Legislative Background and Main Contents of Circular Economy Promotion Law. Legal Work Committee, NPC Standing Committee, National People's Congress, Beijing. In Chinese. Available at: http://www.npc.gov.cn/npc/xinwen/rdlt/fzjs/2008-09/02/content_1447843.htm.

Naustdalslid, J. 2014. Circular economy in China-the environmental dimension of the harmonious society. International Journal of Sustainable Development \& World Ecology 21(4): 303-313.

NBS. 2015. China's national circular economy index in 2013 was 137.6. (2013 年我国循环经济发展

指数为 137.6). National Bureau of Statistics of the People's Republic of China. Beijing. In Chinese. Available at http://www.stats.gov.cn/tjsj/zxfb/201503/t20150318_696673.html.

Parto, S., D. Loorbach, A. Lansink, and R. Kemp. 2007. Transitions and Institutional Change: The Case of the Dutch Waste Subsystem. In Industrial innovation and environmental regulation : developing workable solutions, edited by S. Parto and B. Herbert-Copley: United Nations University Press.

Pearce, D. W. and R. K. Turner. 1990. Economics of natural resources and the environment: JHU Press.

Rydin, Y. and D. Ockwell. 2010. Analysing dominant policy perspectives: the role of discourse analysis. In A Handbook of Environmental Management. , edited by J. Lovett and D. Ockwell. Cheltenham: Edward Elgar.

Shen, K. 2011. Local and central government relations: impulsive investment and sustainable development. In Green China: Chinese insights on environment and development. , edited by J. Keeley and Y. Zheng. London: International Institute for Environment and Development.

Shi, L., L. Xing, J. Bi, and B. Zhang. 2006. Circular Economy: A New Development Strategy for Sustainable Development in China. Paper presented at Third World Congress of Environmental and Resource Economists, Kyoto, Japan.

Stahel, W. R. and G. Reday. 1977. The potential for substituting manpower for energy; report to DG V for Social Affairs, Commission of the EC, Brussels (research contract No. 760137 programme of research and Actions on the development of the Labour Market), study no. 76/13. .

State Council. 2005. Several Opinions of the State Council on accelerating the development of the circular economy (国务院关于加快发展循环经济的若干意见).

State Council. 2013. State Council communication regarding the Circular Economy development strategy and action plan (国务院关于印发循环经济发展战略及近期行动计划的通知). State Council of the People's Republic of China. Beijing. In Chinese. Available online at: http://www.gov.cn/zwgk/2013-02/05/content_2327562.htm.

Su, B., A. Heshmati, Y. Geng, and X. Yu. 2013. A review of the circular economy in China: moving from rhetoric to implementation. Journal of Cleaner Production 42(0): 215-227.

Thieriot, H. and D. Sawyer. 2015. Development of eco-efficient industrial parks in China: a review. IISD Report, International Institute for Sustainable Development, Winnipeg. .

Timmermans, F. 2015. First Vice-President Timmermans' and Vice-President Katainen's opening remarks at the presentation of the Circular Economy package. December 2nd 2015. Transcript published by the European Commission, Brussels. .

Vidal-Legaz, B., L. Mancini, G. A. Blengini, C. Pavel, A. Marmier, D. Blagoeva, C. Latunussa, P. Nuss, J. Dewulf, V. Nita, Y. Kayam, S. Manfredi, A. Magyar, P. Dias, C. Baranzelli, E. Tzimas, and D. 
Pennington. 2016. Raw materials scoreboard. Report published by the European Innovation Partnership on Raw Materials. European Commission, Brussels.

Wang, J. and M. Wang. 2011. Environmental rule of law in China: why the system isn't working. In Chinese insights on environment and development, edited by Y. Zheng and J. Keeley. London: International Institute for Environment and Development.

Weng, X., Z. Dong, Q. Wu, and Y. Qin. 2015. China's path to a green economy: decoding China's green economy concepts and policies. International Institute for Environment and Development.

Young, O. R., D. Guttman, Y. Qi, K. Bachus, D. Belis, H. Cheng, A. Lin, J. Schreifels, S. Van Eynde, Y. Wang, L. Wu, Y. Yan, A. Yu, D. Zaelke, B. Zhang, S. Zhang, X. Zhao, and X. Zhu. 2015. Institutionalized governance processes: Comparing environmental problem solving in China and the United States. Global Environmental Change 31: 163-173.

Yu, C., G. P. Dijkema, and M. Jong. 2015. What Makes Eco-Transformation of Industrial Parks Take Off in China? Journal of Industrial Ecology 19(3): 441-456.

Zhang, L., Z. Yuan, J. Bi, B. Zhang, and B. Liu. 2010. Eco-industrial parks: national pilot practices in China. Journal of Cleaner Production 18(5): 504-509.

Zhao, H., X. Zhu, and Y. Qi. 2016. Fostering Local Entrepreneurship through Regional Environmental Pilot Schemes: The Low-Carbon Development Path of China. China: An International Journal 14(3): 107-130.

Zheng, Y. 2011. China's environment and development challenge. In Chinese insights on environment and development, edited by Y. Zheng and J. Keeley. London: International Institute for Environment and Development. 